\title{
Sleep respiratory disturbances during the ascent to Mount Aconcagua
}

Alvaro Emilio Ortiz-Naretto ${ }^{1,3,4}$ Miriam Patricia Pereiro ${ }^{2,3}$

Glenda Ernst ${ }^{4}$

Eduardo Enrique Borsini ${ }^{4}$

${ }^{1}$ Hospital Francisco Muñiz, Medicine Respiratory Unit - Buenos Aires City Buenos Aires - Argentina.

${ }^{2}$ Hospital Materno Infantil Ramón Sarda, Central Laboratory - Buenos Aires City - Buenos Aires - Argentina. ${ }^{3}$ Asociación Andina de Medicina para la Altura, Curso Medicina para la Altura Mendoza City - Mendoza - Argentina. ${ }^{4}$ Hospital Británico de Buenos Aires, Medicine Respiratory Unit - Buenos Aires City - Buenos Aires - Argentina.

Corresponding author: Alvaro Emilio Ortiz-Naretto.

E-mail: aortiz@intramed.net

E-mail: borsinieduardo@yahoo.com.ar Received: July 27, 2017; Accepted: December 27, 2017.

\begin{abstract}
Introduction: Mountaineers exposed to hypobaric hypoxia $(\mathrm{HH})$ show high-altitude periodic breathing (PB). Objective: To analyze high-altitude PB during the ascent of Mount Aconcagua (Argentina). Materials and Methods: Descriptive study in healthy volunteers using respiratory polygraphy (RP) at different altitudes. Results: We studied 8 andinist, mean age: 36 years old (2551), body mass index (BMI) of 23.6 (20.9-28.7) and 22.77 (20.9-27.7) upon return, $p<0.01$. RP without PB showed a lower Oxygen Desaturation Index (ODI) and a lower Apnea-HypopneaIndex (AHI); $5.43(0-20)$ versus $45.95(2-122) p<0.001$ and $3.9(0-15.5)$ versus 44.35 (4-115) $p<0.001$. AHI increased with altitude at the expense of central apneas and hypopneas: $p<0.05$. Conclusion: High-altitude PB is frequent above 2,581m.a.s.l. And it is characterized by short cycles. None of the mountaineers showed PB at baseline; however, high-altitude PB occurred in all subjects above 4,900 m.a.s.l
\end{abstract}

Keywords: Sleep Apnea, Central; Sleep Apnea Syndromes; Cheyne-Stokes Respiration 


\section{INTRODUCTION}

Acute exposure to high altitude occurs when a person who lives below 2,000 meters above sea level (m.a.s.l.) is exposed to an altitude above 2,000 m.a.s.l. At night, mountaineers exposed to hypobaric hypoxia $(\mathrm{HH})$ may present respiratory disorders. As described by Angelo Mosso in 1898-through simple observation of his brother's breathing pattern during sleep-high-altitude, PB is the most commonly detected ${ }^{1}$. Even though PB may occur above 2,000 m.a.s.l., it prevails above 5,000 m.a.s.l. ${ }^{2}$.

The characteristics of high-altitude PB may differ from semiological descriptions based on data from patients with cardiovascular or neurologic disease, but existing data are scarce $^{2}$. Additionally, there is scant evidence on the effect of acclimatization and no data on the effects of gradual ascent on the semiology of breathing patterns during an expedition.

In order to analyze respiratory cycle alterations during sleep at high altitude and describe temporary changes or changes observed at different levels, we took objective measurements of the breathing patterns of the members of an expedition to Mount Aconcagua. Mountaineers were healthy physicians who volunteered to take part in this study, in context of a mountain medicine course.

\section{MATERIALS AND METHODS}

This was a prospective study on a database made up of systematically collected data from healthy mountaineers who voluntarily enrolled in this study. We conducted a descriptive study using RP recordings obtained at night at different altitudes during the ascent of Mount Aconcagua: 746 m.a.s.l. (Mendoza City-baseline), 2581 m.a.s.l. (Penitentes), 3200 m.a.s.l. (Las Cuevas), 3300 m.a.s.l. (Confluencia), 4300 m.a.s.l. (Plaza de Mulas), 4900m.a.s.l. (Plaza Canadá), 5380 m.a.s.l. (Nido de Cóndores). The expedition, which was part of a research study conducted during a course on Mountain Medicine, left on January 29 and returned on February 15, 2016.

\section{Population}

Eight healthy mountaineers volunteered to take part in the study ( 2 physicians who are experienced mountaineers and acted as guides, and 6 physicians who are non-professional mountaineers). They had no history of respiratory disorders.

\section{Respiratory Polygraphy}

Polygraphic parameters, such as nasal airflow, thoracic effort with qualitative band, and oximetry (average signal time $<1$ second) were measured with level III portable monitors of the American Academy of Sleep Medicine ${ }^{3}$; Apnea Link Plus ${ }^{\circledR}$ (ResMed. Sydney. Australia) with finger pulse oximeter $\left(\mathrm{XPod}^{\circledR}\right.$, Nonin. USA).

All study subjects were trained in the use of polygraphy devices before the ascent. The strategy used during the expedition was self-administered testing ${ }^{4}$. Subjects ascended the mountain together. The entire expedition lasted 17 days (Mendoza-Mendoza).
Respiratory polygraphy recordings were obtained at night in shelters (baseline and lower altitude sites: Penitentes and Las Cuevas), in dome tent shelters (located at the intermediatealtitude campsites known as Confluencia and Plaza de Mulas) and in subjects' tents (in high-altitude campsites known as Plaza Canadá and Nido de Cóndores).

Data obtained from RP recordings were downloaded using specific software and a portable computer. Later, at the Sleep Disorders Unit of Buenos Aires' Hospital Británico, recordings were edited and analyzed manually (sequential manual scoring) using Apnea Link ${ }^{\circledR} 9.0$ software. Only recordings with $>4$ hours of good quality signal over total recording time (TRT)-after edition-were accepted. Manual edition of events was carried out by pulmonologists trained in AASM current standards ${ }^{3,4}$.

Apneas and hypopneas were defined as respiratory events with a $>90 \%$ and $>50 \%$ reduction in nasal airflow, respectively, associated to $\mathrm{a}=3 \%$ drop in oxygen saturation for at least 10 seconds $^{4}$.

AHI was defined as the number of respiratory events (apneas + hypopneas) over valid TRT. After final scoring, recordings were classified either as normal $(\mathrm{AHI}<5 / \mathrm{h})$, mild (AHI between 6 and 14.9 events per hour), moderate (AHI between 15 and 29.9/hour), or severe (AHI > 30/hour). ODI was also calculated over TRT, and the desaturation threshold $(90 \%-85 \%$ and $80 \%)$ was measured in minutes and as a percentage of valid TRT. ODI was defined as 3\% desaturation with respect to the immediately preceding baseline value. Severity categories were the same as those defined for AHI (mild, moderate, and severe).

High-altitude periodic breathing (PB) was identified when the typical polypnea/apnea or crescendo-decrescendo pattern was registered for at least 2 hours of TRT ${ }^{4}$.

In high-altitude PB, we measured cycle duration (from the onset of an apnea event to the beginning of the next event, or from the top of the diamond-like shape in the flow signal to the top of the next one). Analyzed data included 20 measurements in equally set pages with good quality signal (510 minutes). Findings were averaged out in seconds. Finally, the hyperventilation/apnea or hypoventilation phase (when appropriate) was calculated with regard to total cycle duration (Duty Cycle) as a substitute for Edwards and Sands' loop gain ${ }^{2,5}$.

\section{Statistical Analysis}

Results were expressed as mean value, standard error, range or percentage. $\mathrm{P}$ value $(p)<0.05$ was regarded as a statistically significant difference. Investigators used KruskalWallis and Dunn's multiple comparison tests. Tukey test was used to compare multiple measurements.

\section{RESULTS}

Four men and four women took part in the study. Mean age was 36 years old (25-51); BMI at baseline and at the end of the expedition was $23.6(20.9-28.7)$ and 22.8 (20.9-27.7) respectively $(p<0.01)$. 
Forty three sleep polygraphy tests provided valid recordings, four had to be rejected due to a total recording time $<4$ hours (TRT: $<240$ minutes).

Study findings showed that the apnea-hypopnea-index (AHI) increased with altitude at the expense of central apneas and hypopneas; $p<0.05$. The increase in obstructive apneas was not significant (Figure 1).

ODI increased at the last two levels (Figure 2) $p<$ 0.05 and $\mathrm{ST}_{80}$ was the only indicator that showed an elevated correlation; $r$ : 0.85 (CI: $0.71-0.93) p<0.01$, with altitude reached.

The incidence of high-altitude PB was $44.2 \%(19 / 43)$ in the polygraphy recordings of our mountaineers. None of the mountaineers showed PB at baseline; however, high-altitude PB occurred in all subjects above 4,900 m.a.s.l.-the mean height of occurrence being 4,130 (2581-5380 m.a.s.l.)

Moreover, with regard to TRT (PB/TRTx100), highaltitude PB represented $30.9 \%$ and increased with height. PB time represented $23.5 \%$ of TRT at Penitentes (2581 m.a.s.l.), Las Cuevas (3200 m.a.s.l. included Confluencia 3300 m.a.s.l.), $32 \%$ at Plaza de Mulas (4300 m.a.s.l.) and 38.3\% at the highest altitudes reached (Plaza Canada -4900- and Nido de Cóndores -5380-) (Figure 3).

In mountaineers with frequent acute exposure to high altitude (guides), PB/TRTx100 was $12.6 \%$. The rest of the group (sporadic acute exposure) showed PB/TRTx100 of $39.7 \%$ ( $p>0.05)$. High-altitude PB occurred as apnea/polypnea or increasing decreasing with hypopnea.

Guides (2 andinist) presented mainly an increasingdecreasing cycle with 7-11 breaths in the hyperventilation phase. For the rest of the group, high-altitude PB was marked by central apneas and 3-4 breaths in the polypnea phase of the cycle with a wider range of desaturations.

The duration of the high-altitude PB cycle (mean value) was 24.2 (SD: 3.8) seconds both when subjects presented crescendo-decrescendo patterns (Figure 4a) or the typical central apneas with mean hyperventilation/apnea ratio of 0.47 (Figure $4 \mathrm{~b})$. Recordings without high-altitude PB showed lower ODI: 5.43 (range: 0 - 20) versus $45.9(2-122) p<0.001)$ and mean AHI values: $3.9(0-15.5)$ versus $44.35(4-115) p<0.001)$, respectively.

The mean Duty Cycle values measured individually during the ascent did not show any significant differences.

\section{DISCUSSION}

According to most authors, PB is the respiratory event most frequently observed at high altitudes. In general, it occurs above 2000 m.a.s.l. ${ }^{6}$ and presents a characteristic hyperpnoea/ apnea phase ${ }^{2,4,6}$, as we also observed. In our experience, $\mathrm{PB}$ is not evident in the basal polygraphy recording (746 m.a.s.l.), increases with height and is evident in all of them at high altitude (> 4900 m.a.s.l.).

In spite of the low number of participants, as is usual in high-altitude expeditions ${ }^{3}$, we were able to perform many polygraphy tests so as to assess $\mathrm{PB}$ at different altitudes.
Differences found in the morphology of high-altitude $\mathrm{PB}$ in mountain guides and non-professional mountaineers could be related to the acclimatization process through frequent exposure to high altitude and respiratory centers with an altered physiological response to recent $\mathrm{HH}$. We obtained measurements at different altitudes and observed no changes in Duty Cycle or cycle duration during ascent.

This is one of the main differences between our study and other published works that refer only to the hyperpnoea/apnea ${ }^{2,7}$ cycle recordings or compare altitude findings with a preceding baseline value. However, since our measurements lack neurophysiological signals to define "sleep" (electroencephalogram), our findings may be underestimated"

The cycle of high-altitude PB is $<30$ seconds, unlike heart failure-related $\mathrm{PB}$, described as $59 \pm 4.9$ seconds and central or primary PB $37.3 \pm 3$ seconds with $4.5 \pm 0.7$ cycle seconds ${ }^{4,8}$. In our recordings, these cycles were remarkably shorter (24 seconds in average), as in other similarly designed fieldworks ${ }^{2,9}$. Short cycles, as compared to heart failure or idiopathic periodic breathing (IPB), are an important condition in high-altitude $\mathrm{PB}$, even when our recordings presented a curved morphology with two patterns, as in PB.

It is worth highlighting that the recommended definition of $\mathrm{PB}$ in polysomnographic recordings ${ }^{4}$ does not exactly apply to highaltitude $\mathrm{PB}$, because of cycle duration criteria. There is no universal definition of high-altitude PB for polygraphy test measurements.

There are two mechanisms that may account for high-altitude PB: ventilatory response to hypoxia and carbon dioxide threshold $\left(\mathrm{CO}_{2}\right)$. At high altitude, $\mathrm{HH}$ produces initial response, tachypnea and polypnea that lead to a drop in $\mathrm{CO}_{2}$ and an increased heart rate. The increased blood flow to the brain related with hyperventilation leads to low arterial $\mathrm{CO}_{2}$ during sleep, the respiratory center has a higher $\mathrm{CO}_{2}$ threshold that leads to apnea, rapidly increasing the concentration of $\mathrm{CO}_{2}$. Compensating polypnea is the response to this rapid increase in $\mathrm{CO}_{2}$. Typical $\mathrm{PB}$ occurs because inhalation of $\mathrm{CO}_{2}$ at high altitude only eliminates apnea but not periodicity, which is eliminated with oxygen supply $y^{5,10}$. With gradual ascent, especially at extreme altitudes (4900 and 5380 m.a.s.l. in our experience), The $\mathrm{PB}$ is not evident in the basal polygraphs (746 m.a.s.l.), increases with height and is evident in all of them at high altitude (> 4900 m.a.s.l.) Figure 3.

AHI increases at the expense of central apneas (Figure 1b) due to typical high-altitude PB (Figure 4 A) and, to a lesser degree, hypopneas (Figure 1c).

Our conclusions, however, are limited by the fact that we lack objective $\mathrm{CO}_{2}$ measurements.

In frequent or recent $\mathrm{HH}$ exposure (mountain guides), acclimatization of the respiratory center and peripheral chemoreceptors affected by $\mathrm{CO}_{2}$ variations from previous exposure would respond differently with increasing/decreasing patterns without apnea. Response to $\mathrm{CO}_{2}$ would be more compliant to hypoxia, which would favor high altitude $\mathrm{PB}^{2,9}$. However, the characteristics of Duty Cycle as a substitute for loop gain did not change in our study subjects. 
A)

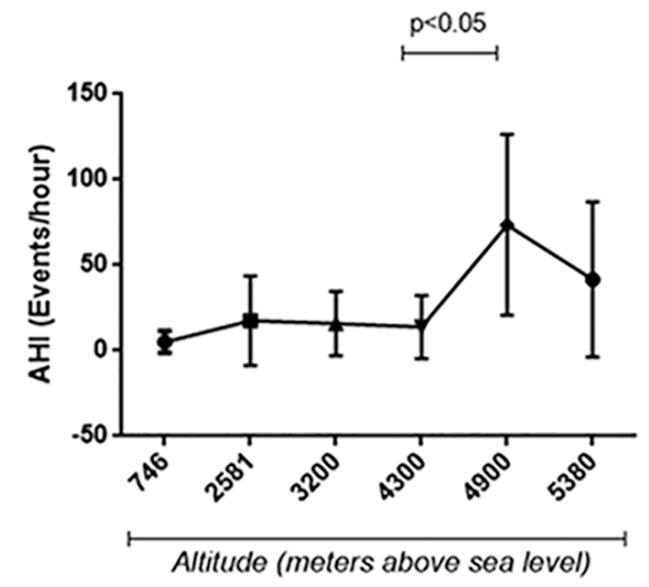

C)

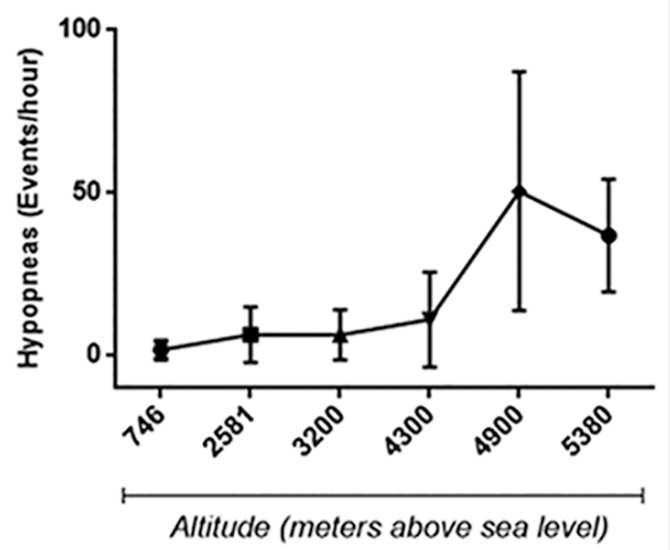

B)

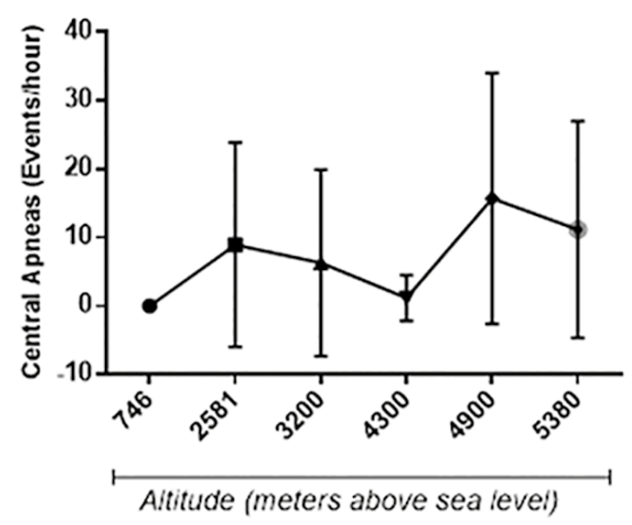

D)

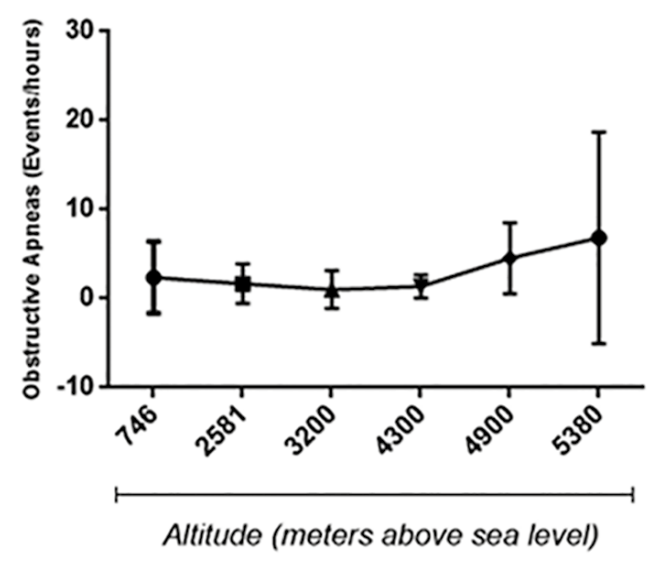

Figure 1. Increase in AHI observed at higher altitudes. Gradual increase in the number of central apneas and hypopneas with regard to altitude above sea level. Note the marked increase in the number of events recorded above 4300 m.a.s.l. relationship between obstructive apneas and height (not statiscally significant).

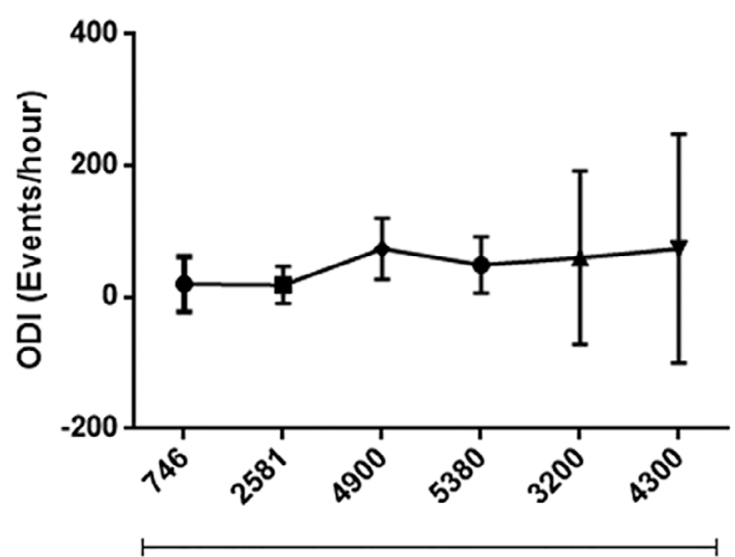

Altitude (meters above sea level)

Figure 2. Oxygen desaturation index (ODI) per hour; 3\% threshhold with regard to ascent.

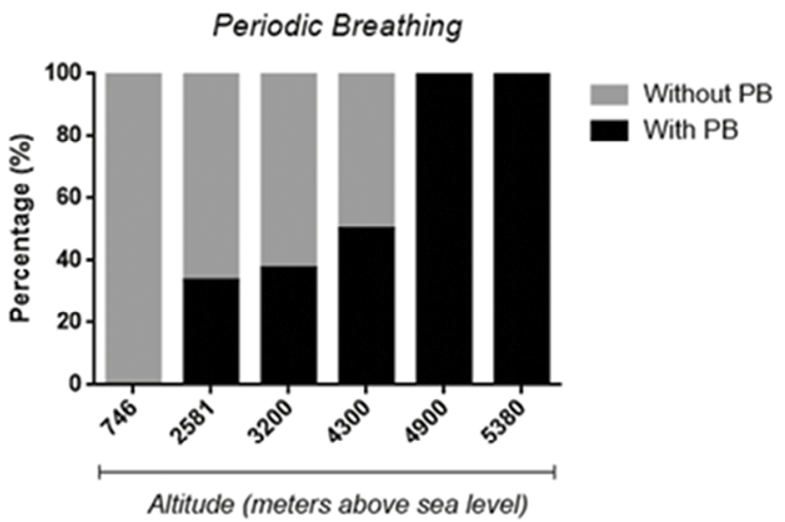

Figure 3. PB identified during ascent to higher altitudes above sea level. The PB is not evident in the basal polygraphy recording $(746 \mathrm{msnm})$, increases with height and is evident in all of them at high altitude (> 4900 m.a.s.l.). 


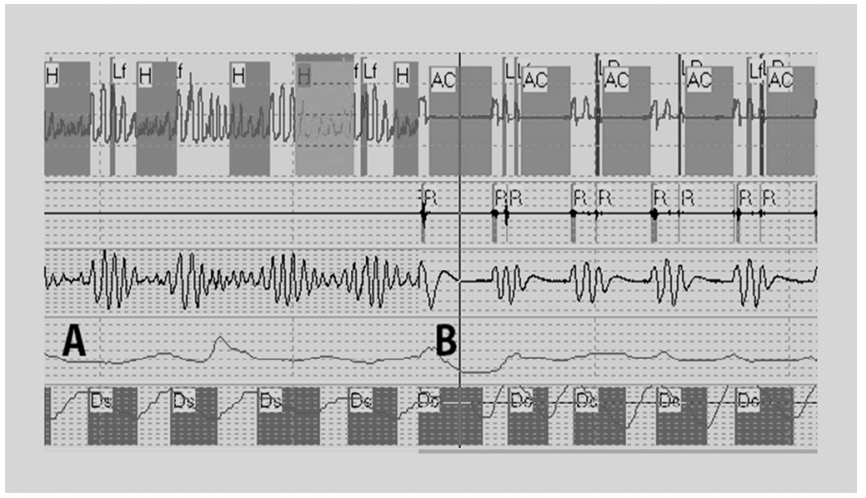

Figure 4. A. Increasing / decreasing PB with hypopnea, B. apnea/hyperpnoea PB with apnea central.

\section{CONCLUSIONS}

Above 2581 m.a.s.l., high-altitude PB and central apneas were frequent findings in healthy mountaineers. Subjects with frequent acute exposure presented fewer central apneas with increasing/ decreasing cycles and hypopneas and similar duration cycles.

The characteristics of high-altitude PB differ from idiopathic and heart failure-related PB, since high-altitude PB presents shorter cycles.

\section{Acknowledgment}

Collaborative group to study of respiratory disturbance in high altitude. Lofti M, Pronce R, Bertok L, Ahlfeld BAM, Vazquez A, Onofri E and Asociación Andina de Medicina para la Altura.

To ResMed LATAM for the donation of respiratory polygraphy devices used during the expedition.

\section{REFERENCES}

1. Mosso A. Respiration on the Mountains. In: Mosso A. Life of Man on the High Alps. London: T Fisher Unwin; 1898. p. 31-50.

2. Andrews G, Ainslie PN, Shepherd K, Dawson A, Swart M, Lucas S, et al. The effect of partial acclimatization to high altitude on loop gain and central sleep apnoea severity. Respirology. 2012;17(5):835-40. DOI http://dx.doi.org/10.1111/j.1440-1843.2012.02170.x

3. Ernst G, Bosio M, Salvado A, Nogueira F, Nigro C, Borsini E. Comparative Study between Sequential Automatic and Manual Home Respiratory Polygraphy Scoring Using a Three-Channel Device: Impact of the Manual Editing of Events to Identify Severe Obstructive Sleep Apnea. Sleep Disord. 2015;2015:314534. DOI: http://dx.doi. org $/ 10.1155 / 2015 / 314534$

4. Berry RB, Budhiraja R, Gottlieb DJ, Gozal D, Iber C, Kapur VK, et al.; American Academy of Sleep Medicine. Rules for scoring respiratory events in sleep: update of the 2007 AASM Manual for the Scoring of Sleep and Associated Events. Deliberations of the Sleep Apnea Definitions Task Force of the American Academy of Sleep Medicine. J Clin Sleep Med. 2012;8(5):597-619.

5. Edwards BA, Sands SA, Owens RL, White DP, Genta PR, Butler JP et al. Effects of hyperoxia and hypoxia on the physiological traits responsible for obstructive sleep apnoea. J Physiol. 2014;592(20):4523 35. PMID: 25085887 DOI: http://dx.doi.org/10.1113/jphysiol.2014.277210

6. Burgess KR, Ainslie PN. Central Sleep Apnea at High Altitude. Adv Exp Med Biol. 2016;903:275-83.

7. West JB, Peters RM Jr, Aksnes G, Maret KH, Milledge JS, Schoene RB. Nocturnal periodic breathing at altitude of 6,300 and $8,050 \mathrm{~m}$. J Appl Physiol (1985). 1986;61(1):280-7. DOI: http://dx.doi.org/10.1152/ jappl.1986.61.1.280

8. Hall MJ, Xie A, Rutherford, Ando S, Floras JS, Bradley TD, et al. Cycle length of periodic breathing in patients with and without heart failure. Am J Respir Crit Care Med. 1996;154(2 Pt 1):376-81. DOI: http:// dx.doi.org/10.1164/ajrccm.154.2.8756809

9. Nussbaumer-Ochsner Y, Ursprung J, Siebenmann C, Maggiorini M, Bloch KE. Effect of short term acclimatization to high altitude on sleep and nocturnal breathing. Sleep. 2012;35(3):419-23. DOI: http:// dx.doi.org/10.5665/sleep. 1708

10. Lahiri S, Maret K, Sherpa MG. Dependence of high altitude sleep apnea on ventilatory sensitivity to hypoxia. Respir Physiol. 1983;52(3):281 301. DOI: http://dx.doi.org/10.1016/0034-5687(83)90086-5 